\title{
ROTAVIRUS GASTROENTERITIS IN HOSPITAL SPECIALIZING IN CHILDREN WITH CRANIOFACIAL MALFORMATIONS
}

THESIS. N. A. Vieira submitted this dissertation for her Masters in Tropical Diseases at Botucatu School of Medicine, São Paulo State University, UNESP, Botucatu, São Paulo, Brazil, 2004.

Advisor: Professor Paulo Câmara Marques Pereira

\begin{abstract}
The object of this research was to verify the occurrence of rotavirus diarrhea in 8,724 children below five years of age, who were under the care of Craniofacial Anomalies Rehabilitation Hospital - São Paulo University (HRAC - USP), in Bauru, with the help of laboratorial, clinical, socioeconomic and cultural indicators between January 2000 and December 2002. The present study evaluated and compared three groups of children, 62 with diarrhea and rotavirus infection, 153 with diarrhea, and 8,509 without diarrhea. Patients came from various Brazilian States. It was demonstrated that the low social-economics level was predominant in all the groups. There was no difference in sex distribution. All groups were predominantly white. From the total rotavirus gastroenteritis it was shown that $29.03 \%$ were due to hospital infection, and the patients check-in time was associated. In $38.71 \%$ of children with rotavirus gastroenteritis, age group was inferior to six months. The percentage of not breast-fed children was significantly higher in the diarrhea groups. In children with diarrhea, it was observed that approximately half of them presented hemoglobin serum levels below the normal and that their weight/age percentage was inferior to ten. The leukocytes and lymphocytes values were within the normal levels in the majority of children with diarrhea. Seasonality in the occurrence of rotavirus, predominantly between May and October, was also observed. Further investigations could shed light on possible agents causing diarrhea in children with craniofacial malformations.
\end{abstract}

KEY WORDS: rotavirus, diarrhea, gastroenteritis, enteropathogens, epidemiology

\section{CORRESPONDENCE TO:}

PAULO CÂMARA MARQUES PEREIRA, Departamento de Doenças Tropicais e Diagnóstico por Imagem, Faculdade de Medicina de Botucatu, UNESP, Distrito de Rubião Junior, s/n, 18618-000, Botucatu, SP, Brasil, Phone: 551438116212. Email: ppereira@fmb.unesp.br 